\title{
Focal necrosis and disturbed myelination in the white matter of newborn infants: a tale of too much or too little oxygen
}

\author{
Sven Wellmann ${ }^{1}$, Christoph Bührer ${ }^{2}{ }^{*}$ and Thomas Schmitz ${ }^{2}$ \\ 1 Division of Neonatology, University Children's Hospital, Basel, Switzerland \\ ${ }^{2}$ Department of Neonatology, Charité University Medical Center, Berlin, Germany
}

Edited by:

Giuseppina Milano, Centre Hospitalier

Universitaire Vaudois, Switzerland

\section{Reviewed by:}

Celia Camille Maneri, Valley

Anesthesiology Consultants, USA

Yasuhiro Fujii, Stanford University,

USA

\section{${ }^{*}$ Correspondence:}

Christoph Bührer, Klinik für

Neonatologie, Charité

Universitätsmedizin Berlin, D-13344

Berlin, Germany

e-mail: christoph.buehrer@charite.de
White matter disease in preterm infants comes along with focal destructions or with diffuse myelination disturbance. Recent experimental work with transgenic mice paves the way for a unifying molecular model for both types of brain injury, placing oxygen sensing by oligodendrocyte precursor cells (OPCs) at the center stage. Mice genetically altered to mimic high local oxygen tension in oligodendroglia lineage cells (via deletion of hypoxia-inducible factor, HIF) develop white matter disease resembling cystic periventricular leukomalacia within the first 7 days of life. Mice in which local hypoxia is mimicked in oligodendroglial cells (via genetic inhibition of HIF decay) display arrested OPC maturation and subsequent hypomyelination, reminiscent of the diffuse white matter disease observed in preterm infants and infants with congenital heart disease. These recent experimental findings on oxygen sensing and myelination are awaiting integration into a clinical framework. Gene regulation in response to hyperoxia or hypoxia, rather than oxidative stress, may be an important mechanism underlying neonatal white matter disease.

Keywords: periventricular leukomalacia, white matter disease, hypoxia-inducible factor, oligodendrocyte precursors, myelination

\section{CYSTIC AND DIFFUSE WHITE MATTER DISEASE IN NEWBORN INFANTS}

Brain injury in preterm newborn infants involves both destructive and developmental disturbances (1). Cystic periventricular leukomalacia $(\mathrm{cPVL})$ and diffuse white matter disease (dWMD) are increasingly being viewed as distinct nosological entities rather representing various degrees of severity of the same disorder $(2,3)$. cPVL is characterized by non-hemorrhagic necrotic lesions leading to non-selective destruction of all cellular elements, including glia and blood vessels $(1,4)$. These lesions are usually detected as clustered or sporadic porencephalic cysts by cranial ultrasound during the second or third week of life (5). While the incidence of cPVL declined in recent decades, with cPVL affecting now less than $5 \%$ of very low birth weight infants (6-9), it remains the strongest predictor of severe cerebral palsy in preterm infants (10). Risk factors for CPVL differ from those of most other prematurity related diseases, as rates of cPVL do not increase with low Apgar scores, lack of antenatal steroids, institution or duration of mechanical ventilation, male sex, or extremely low gestational age (11). Among very low birth weight infants, rates of CPVL are not related to gestational age $(6,11)$ while the overall risk of neurodevelopmental impairment rises steadily with decreasing gestational age.

Evidence of dWMD has been revealed by advanced magnetic resonance imaging techniques, notably diffusion tensor imaging and magnetic resonance spectroscopy imaging, in many very low birth weight preterm infants $(9,12-14)$. Moreover, magnetic resonance imaging studies in infants with congenital heart disease have revealed dWMD in a substantial proportion of these infants after neonatal cardiac surgery $(15,16)$. Some of these lesions, however, are present already before cardiac surgery (17-19). The clinical sequelae of dWMD appear to be more subtle, as compared to those of CPVL, and include cognitive and behavioral problems such as attention deficits, hyperactivity, language impairments, and poor processing of visual information (20-24). Autopsy findings point to disturbed myelination, arising from failure of oligodendrocyte precursor cells (OPCs) to generate myelinating oligodendrocytes, as a key finding in dWMD (8). In contrast to CPVL, there is little axonal degeneration (25) or loss of gray matter neurons in dWMD (26). However, the complexity of dendritic arbors is reduced in dWMD, and the transient failure to establish neuronal connections is thought to underlie persistently altered brain circuitry (2).

\section{OXYGEN-REGULATED GENE EXPRESSION}

Changes of ambient oxygen tension cause a cellular response orchestrated by hypoxia-inducible factors (HIFs) in almost all mammalian cell types (27). The lack of oxygen (hypoxia) strongly activates the master regulators HIF1 and HIF2, normal oxygen tension or an excess in oxygen (hyperoxia) blocks the action of both transcription factors. In detail, HIF1 and HIF2 are two heterodimeric transcription factors consisting each of an oxygen-regulated $\alpha$-subunit (HIF $1 \alpha$ and HIF $2 \alpha$ ) and an oxygeninsensitive $\beta$-subunit. In the presence of oxygen, HIF $1 \alpha$ and HIF $2 \alpha$ are permanently deactivated by two oxygen-dependent enzymes, asparaginyl and prolyl hydroxylases. Asparagine hydroxylation of a conserved residue inhibits the binding of HIF $1 \alpha$ or HIF $2 \alpha$ to its coactivator p300/CREB-binding protein (28). Proline hydroxylation 
targets HIF $1 \alpha$ or HIF2 $\alpha$ for ubiquitination mediated by the von Hippel-Lindau (VHL) ubiquitin ligase $(29,30)$, which in turn is followed by proteasomal degradation (31). The enzymatic activity of both, the asparginyl and prolyl hydroxylase, is lowered or even turned off at low oxygen tension, as they both use oxygen as a substrate. Subsequently, spared HIF $1 \alpha$ and HIF $2 \alpha$ moieties are then able to join oxygen-insensitive $\beta$ subunits, translocate to the nucleus, and activate a distinct gene response.

\section{WHITE MATTER DISEASE IN MICE WITH GENETICALLY ALTERED HIF METABOLISM}

As intrauterine oxygen tension is difficult to manipulate in experimental animals, researchers at the University of California in San Francisco used mice with either targeted deletions of HIF $1 \alpha$ and HIF $2 \alpha$, or lack of VHL-mediated HIF $1 \alpha / \mathrm{HIF} 2 \alpha$ decay in the oligodendroglial lineage (32). Embryonic mice unable to express HIF $1 \alpha$ and HIF2 $\alpha$ in oligodendroglial lineage cells, mimicking high local oxygen tension, had poor vascularization in the white matter before birth, followed by severe neuroaxonal damage and apoptotic cell death of microglia, astroglia, and oligodendroglia by day 4 of life, and ultimately acellular white matter cysts by day 7 of life. In contrast, conditional oligodendroglial HIF $1 \alpha / H I F 2 \alpha$ overexpression mediated by VHL knockout resulted in OPC maturation arrest and subsequent hypomyelination. By using genetically engineered mice with manipulated HIF pathways but kept in normal air, the study specifically investigated the effects of oxygen-sensitive gene regulation, as there was neither oxidative stress associated with excessive oxygen, nor low intracellular energy stores occurring when oxygen supply fails to meet demands. Nevertheless, the delayed OPC differentiation and reduced expression of myelin basic protein observed with VHL knockout-mediated HIF $1 \alpha / \mathrm{HIF} 2 \alpha$ overexpression was also observed in wild-type mice exposed to hypoxia $\left(\mathrm{FiO}_{2} 0.1\right)$ between day 3 and 11 of life.

The investigators went on to show that the regulation of white matter vascularization and oligodendroglial maturation in response to altered $\mathrm{HIF} 1 \alpha / \mathrm{HIF} 2 \alpha$ is mediated by secreted Wnt7a/7b glycoproteins in a paracrine or autocrine fashion, respectively. Wnt7a/7b was previously implicated in oligodendroglial maturation and myelination $(33,34)$, as well as in white matter vascularization (35), and the new work now demonstrates its regulation by $\mathrm{HIF} 1 \alpha / \mathrm{HIF} 2 \alpha$. Chronic hypoxia $\left(\mathrm{FiO}_{2} 0.1\right.$ for $6-72 \mathrm{~h}$ ) has recently been shown to induce canonical ( $\beta$-catenindependent) Wnt signaling alongside increased cell proliferation in the hippocampus of adult mice (36). In the white matter, the role of Wnt7a/7b is reminiscent of vascular endothelial growth factor (VEGF) as the classical HIF $1 \alpha / \mathrm{HIF} 2 \alpha$ target that is involved in angiogenesis and tissue architecture in the gray matter (37).

\section{EFFECTS OF HYPOXIA OR HYPEROXIA ON THE BRAIN OF NEWBORN RODENTS}

In the report that first used the term "periventricular leukomalacia" (38), the authors concluded from the location of the lesions at arterial border zones that either a lack of oxygen or an excess of oxygen might contribute to the pathogenesis of the neonatal white matter disease described (39). Mouse or rat pups subjected to antenatal hypoxia $\left(\mathrm{FiO}_{2} 0.1\right)$ show increased white matter vessel densities but myelination deficits are only found in rat pups (40). The oligodendroglial maldevelopment and the delay of myelination observed in neonatal rats are aggravated by postnatal hyperoxia $\left(\mathrm{FiO}_{2} 0.6\right.$ for 7 days) but prevented by slowly increasing $\mathrm{FiO}_{2}$ from 0.15 to 0.21 during the first 7 days of life (41). Mice pups reared under low oxygen $\left(\mathrm{FiO}_{2} 0.1\right)$ between day 3 and day 11 of life display reduced cortical gray and white matter volumes and delayed maturation of OPCs (42). Experimental hypoxia, however, does not elicit the cPVL-type focal necrotic lesions involving all cellular elements, unless cerebral blood supply is drastically perturbed (3). In contrast, the clinical course of preterm infants subsequently diagnosed with cPVL is often inconspicuous, and their mean arterial blood pressures during the first week of life are higher than those of controls (11). A role for cerebral vessel constriction in precipitating CPVL has been inferred from the relationship between cPVL and hypocapnia during the first days of life $(11,43,44)$ and the increased rates of cerebral palsy and impaired neurodevelopment associated with neonatal hypocapnia and hyperoxia $(45,46)$. The work by Yuen et al. (32) suggests that degeneration of white matter vessels mediated by loss of trophic Wnt7a/7b stimulation in response to relative hyperoxia may promote the focal ischemic infarctions that underlie cPVL. cPVL thus joins retinopathy of prematurity (ROP) as a disease of developing arterial blood vessel that is driven by the rapid surge of oxygen tension that invariably follows lung aeration after birth.

The transition from placental to pulmonary oxygenation causes a rapid, drastic and persistent increase of oxygen tension. Oxygen tensions measured in fetal brain are only $10-20 \%$ of those found in adult brain $(0.08-7.6 \mathrm{mmHg}$ vs. $11-53 \mathrm{mmHg})(47)$, and the huge oxygen leap after birth necessarily diminishes expression of HIF $1 \alpha /$ HIF $2 \alpha$-regulated genes. Human embryonic stem cells can give rise to oligodendroglial lineage cells in vitro when cultured at low oxygen of $\mathrm{FiO}_{2} 0.03$ but not at $\mathrm{FiO}_{2} 0.21(48,49)$. In preterm infants, developmental processes, which physiologically ought to continue for several months under low oxygen conditions (and therefore in the presence of high concentrations of VEGF, Wnt7a/7b, and a multitude of other HIF $1 \alpha /$ HIF $2 \alpha$-regulated gene products) are suddenly disturbed or disrupted by premature birth into room air, even if additional supply of oxygen is being avoided. Restraint in using high $\mathrm{FiO}_{2}$ with careful monitoring of arterial oxygen saturation by pulse oximetry might have contributed to the decline of cPVL observed over the last decades (6-9).

While experimental hyperoxia in rodents is apt to reproduce several findings of human ROP, exposure to neonatal rats or mice to high oxygen does not necessarily generate the cystic white matter lesions observed with gene-mediated HIF $1 \alpha / \mathrm{HIF} 2 \alpha$-suppression in OPCs acting already before birth. While the brain maturation of newborn rats and mice recapitulates many features of the human situation during the last trimester of pregnancy and therefore that of preterm infants born 2-3 months early, the newborn rodents used in experiments are physiologically adjusted to the perinatal oxygen surge and thus potentially less vulnerable than human preterm babies. Experimental hyperoxia at birth $\left(\mathrm{FiO}_{2}\right.$ $0.6)$, postnatal day 3 or day $6\left(\mathrm{FiO}_{2} 0.6\right)$, but not day 10 , has nevertheless a deleterious effect on the developing white matter in normal rat pups $(41,50)$. Grown-up mice (30 or 60 days old) previously exposed to hyperoxia $\left(\mathrm{FiO}_{2} 0.8\right)$ at 6 days of life for $48 \mathrm{~h}$ 
continue to show signs of dWMD when examined by diffusion tensor imaging (51) that reflect myelination abnormalities and consecutive axonopathies (52). Cultured OPCs but not mature oligodendrocytes undergo apoptotic cell death when directly subjected to high oxygen $(50,53)$ but it is unknown whether this also involves HIF $1 \alpha / \mathrm{HIF} 2 \alpha$-mediated downregulation of trophic factors or other non-HIF1 $\alpha /$ HIF $2 \alpha$-mediated mechanisms.

\section{CONCLUDING REMARKS}

In sum, the immature white matter of both human beings and rodents is highly sensitive to altered oxygen tension during a critical developmental window prior to the onset of myelination. Both too much and too little oxygen can cause damage by profoundly altering expression of various genes, unrelated to any oxidative stress. These two conditions may occur sequentially in the same brain, as reduced vessel density after high oxygen subsequently leads to low oxygen supply at a time when demand is on the rise. Meticulous attempts to avoid extremes of oxygen tension in the brains of preterm infants and in infants with congenital heart disease undergoing surgery, possibly aided by directly monitoring cerebral oxygenation (54), will hopefully further preserve their white matter integrity.

\section{REFERENCES}

1. Volpe JJ. Brain injury in premature infants: a complex amalgam of destructive and developmental disturbances. Lancet Neurol (2009) 8(1):110-24. doi:10. 1016/S1474-4422(08)70294-1

2. Back SA, Miller SP. Brain injury in premature neonates: a primary cerebral dysmaturation disorder? Ann Neurol (2014) 75(4):469-86. doi:10.1002/ana.24132

3. Back SA, Rosenberg PA. Pathophysiology of glia in perinatal white matter injury. Glia (2014) 62(11):1790-815. doi:10.1002/glia.22658

4. Gilles FH, Gomez IG. Developmental neuropathology of the second half of gestation. Early Hum Dev (2005) 81(3):245-53. doi:10.1016/j.earlhumdev.2005. 01.005

5. Kuban KC, Allred EN, Dammann O, Pagano M, Leviton A, Share J, et al. Topography of cerebral white-matter disease of prematurity studied prospectively in 1607 very-low-birthweight infants. J Child Neurol (2001) 16(6):401-8. doi:10.2310/7010.2001.7162

6. Hamrick SE, Miller SP, Leonard C, Glidden DV, Goldstein R, Ramaswamy V, et al. Trends in severe brain injury and neurodevelopmental outcome in premature newborn infants: the role of cystic periventricular leukomalacia. J Pediatr (2004) 145(5):593-9. doi:10.1016/j.jpeds.2004.05.042

7. Groenendaal F, Termote JU, van der Heide-Jalving M, van Haastert IC, de Vries LS. Complications affecting preterm neonates from 1991 to 2006: what have we gained? Acta Paediatr (2010) 99(3):354-8. doi:10.1111/j.1651-2227. 2009.01648.x

8. Buser JR, Maire J, Riddle A, Gong X, Nguyen T, Nelson K, et al. Arrested preoligodendrocyte maturation contributes to myelination failure in premature infants. Ann Neurol (2012) 71(1):93-109. doi:10.1002/ana.22627

9. Chau V, Synnes A, Grunau RE, Poskitt KJ, Brant R, Miller SP. Abnormal brain maturation in preterm neonates associated with adverse developmental outcomes. Neurology (2013) 81(24):2082-9. doi:10.1212/01.wnl.0000437298. 43688.b9

10. Vohr BR, Wright LL, Poole WK, McDonald SA. Neurodevelopmental outcomes of extremely low birth weight infants <32 weeks' gestation between 1993 and 1998. Pediatrics (2005) 116(3):635-43. doi:10.1542/peds.2004-2247

11. Shankaran S, Langer JC, Kazzi SN, Laptook AR, Walsh M; National Institute of Child Health and Human Development Neonatal Research Network. Cumulative index of exposure to hypocarbia and hyperoxia as risk factors for periventricular leukomalacia in low birth weight infants. Pediatrics (2006) 118(4):1654-9. doi:10.1542/peds.2005-2463

12. Pandit AS, Ball G, Edwards AD, Counsell SJ. Diffusion magnetic resonance imaging in preterm brain injury. Neuroradiology (2013) 55(Suppl 2):65-95. doi:10.1007/s00234-013-1242-x
13. Kendall GS, Melbourne A, Johnson S, Price D, Bainbridge A, Gunny R, et al. White matter NAA/Cho and Cho/Cr ratios at MR spectroscopy are predictive of motor outcome in preterm infants. Radiology (2014) 271(1):230-8. doi:10.1148/radiol.13122679

14. Alexandrou G, Mårtensson G, Skiöld B, Blennow M, Adén U, Vollmer B. White matter microstructure is influenced by extremely preterm birth and neonatal respiratory factors. Acta Paediatr (2014) 103(1):48-56. doi:10.1111/apa.12445

15. Galli KK, Zimmerman RA, Jarvik GP, Wernovsky G, Kuypers MK, Clancy RR, et al. Periventricular leukomalacia is common after neonatal cardiac surgery. $J$ Thorac Cardiovasc Surg (2004) 127(3):692-704. doi:10.1016/j.jtcvs.2003.09.053

16. Beca J, Gunn JK, Coleman L, Hope A, Reed PW, Hunt RW, et al. New white matter brain injury after infant heart surgery is associated with diagnostic group and the use of circulatory arrest. Circulation (2013) 127(9):971-9. doi:10.1161/CIRCULATIONAHA.112.001089

17. Miller SP, McQuillen PS, Hamrick S, Xu D, Glidden DV, Charlton N, et al. Abnormal brain development in newborns with congenital heart disease. N Engl J Med (2007) 357(19):1928-38. doi:10.1056/NEJMoa067393

18. Rios DR, Welty SE, Gunn JK, Beca J, Minard CG, Goldsworthy M, et al. Usefulness of routine head ultrasound scans before surgery for congenital heart disease. Pediatrics (2013) 131(6):e1765-70. doi:10.1542/peds.2012-3734

19. Goff DA, Shera DM, Tang S, Lavin NA, Durning SM, Nicolson SC, et al. Risk factors for preoperative periventricular leukomalacia in term neonates with hypoplastic left heart syndrome are patient related. J Thorac Cardiovasc Surg (2014) 147(4):1312-8. doi:10.1016/j.jtcvs.2013.06.021

20. Woodward LJ, Clark CA, Bora S, Inder TE. Neonatal white matter abnormalities an important predictor of neurocognitive outcome for very preterm children. PLoS One (2012) 7(12):e51879. doi:10.1371/journal.pone.0051879

21. Pogribna U, Yu X, Burson K, Zhou Y, Lasky RE, Narayana PA, et al. Perinatal clinical antecedents of white matter microstructural abnormalities on diffusion tensor imaging in extremely preterm infants. PLoS One (2013) 8(8):e72974. doi:10.1371/journal.pone.0072974

22. Reidy N, Morgan A, Thompson DK, Inder TE, Doyle LW, Anderson PJ. Impaired language abilities and white matter abnormalities in children born very preterm and/or very low birth weight. J Pediatr (2013) 162(4):719-24. doi:10.1016/j.jpeds.2012.10.017

23. Thompson DK, Lee KJ, Egan GF, Warfield SK, Doyle LW, Anderson PJ, et al. Regional white matter microstructure in very preterm infants: predictors and 7 year outcomes. Cortex (2014) 52:60-74. doi:10.1016/j.cortex.2013.11.010

24. Rollins CK, Watson CG, Asaro LA, Wypij D, Vajapeyam S, Bellinger DC, et al. White matter microstructure and cognition in adolescents with congenital heart disease. J Pediatr (2014) 165(5): 936-44.e2. doi:10.1016/j.jpeds.2014.07.028

25. Riddle A, Maire J, Gong X, Chen KX, Kroenke CD, Hohimer AR, et al. Differential susceptibility to axonopathy in necrotic and non-necrotic perinatal white matter injury. Stroke (2012) 43(1):178-84. doi:10.1161/STROKEAHA.111.632265

26. Pierson CR, Folkerth RD, Billiards SS, Trachtenberg FL, Drinkwater ME, Volpe JJ, et al. Gray matter injury associated with periventricular leukomalacia in the premature infant. Acta Neuropathol (2007) 114(6):619-31. doi:10.1007/s00401007-0295-5

27. Loboda A, Jozkowicz A, Dulak J. HIF-1 and HIF-2 transcription factors - similar but not identical. Mol Cells (2010) 29(5):435-42. doi:10.1007/s10059-0100067-2

28. Lando D, Peet DJ, Whelan DA, Gorman JJ, Whitelaw ML. Asparagine hydroxylation of the HIF transactivation domain a hypoxic switch. Science (2002) 295(5556):858-61. doi:10.1126/science.1068592

29. Jaakkola P, Mole DR, Tian YM, Wilson MI, Gielbert J, Gaskell SJ, et al. Targeting of HIF-alpha to the von Hippel-Lindau ubiquitylation complex by O2regulated prolyl hydroxylation. Science (2001) 292(5516):468-72. doi:10.1126/ science. 1059796

30. Ivan M, Kondo K, Yang H, Kim W, Valiando J, Ohh M, et al. HIFalpha targeted for VHL-mediated destruction by proline hydroxylation: implications for O2 sensing. Science (2001) 292(5516):464-8. doi:10.1126/science.1059817

31. Maxwell PH, Wiesener MS, Chang GW, Clifford SC, Vaux EC, Cockman ME, et al. The tumour suppressor protein VHL targets hypoxia-inducible factors for oxygen-dependent proteolysis. Nature (1999) 399(6733):271-5. doi:10.1038/ 20459

32. Yuen TJ, Silbereis JC, Griveau A, Chang SM, Daneman R, Fancy SP, et al. Oligodendrocyte-encoded HIF function couples postnatal myelination and white matter angiogenesis. Cell (2014) 158(2):383-96. doi:10.1016/j.cell.2014. 04.052 
33. Fancy SP, Baranzini SE, Zhao C, Yuk DI, Irvine KA, Kaing S, et al. Dysregulation of the Wnt pathway inhibits timely myelination and remyelination in the mammalian CNS. Genes Dev (2009) 23(13):1571-85. doi:10.1101/gad.1806309

34. Feigenson K, Reid M, See J, Crenshaw EB III, Grinspan JB. Wnt signaling is sufficient to perturb oligodendrocyte maturation. Mol Cell Neurosci (2009) 42(3):255-65. doi:10.1016/j.mcn.2009.07.010

35. Daneman R, Agalliu D, Zhou L, Kuhnert F, Kuo CJ, Barres BA. Wnt/beta-catenin signaling is required for CNS, but not non-CNS, angiogenesis. Proc Natl Acad Sci U S A (2009) 106(2):641-6. doi:10.1073/pnas.0805165106

36. Varela-Nallar L, Rojas-Abalos M, Abbott AC, Moya EA, Iturriaga R, Inestrosa NC. Chronic hypoxia induces the activation of the Wnt/beta-catenin signaling pathway and stimulates hippocampal neurogenesis in wild-type and APPswe-PS1DeltaE9 transgenic mice in vivo. Front Cell Neurosci (2014) 8:17. doi:10.3389/fncel.2014.00017

37. Li S, Haigh K, Haigh JJ, Vasudevan A. Endothelial VEGF sculpts cortical cytoarchitecture. J Neurosci (2013) 33(37):14809-15. doi:10.1523/JNEUROSCI.136813.2013

38. Banker BQ, Larroche JC. Periventricular leukomalacia of infancy. A form of neonatal anoxic encephalopathy. Arch Neurol (1962) 7:386-410. doi:10.1001/ archneur.1962.04210050022004

39. Elitt CM, Rosenberg PA. The challenge of understanding cerebral white matter injury in the premature infant. Neuroscience (2014) 276:216-38. doi:10.1016/j. neuroscience.2014.04.038

40. Fontaine RH, Olivier P, Massonneau V, Leroux P, Degos V, Lebon S, et al. Vulnerability of white matter towards antenatal hypoxia is linked to a speciesdependent regulation of glutamate receptor subunits. Proc Natl Acad Sci U S A (2008) 105(43):16779-84. doi:10.1073/pnas.0803004105

41. Vottier G, Pham H, Pansiot J, Biran V, Gressens P, Charriaut-Marlangue C, et al. Deleterious effect of hyperoxia at birth on white matter damage in the newborn rat. Dev Neurosci (2011) 33(3-4):261-9. doi:10.1159/000327245

42. Jablonska B, Scafidi J, Aguirre A, Vaccarino F, Nguyen V, Borok E, et al. Oligodendrocyte regeneration after neonatal hypoxia requires FoxO1-mediated p27Kip1 expression. J Neurosci (2012) 32(42):14775-93. doi:10.1523/JNEUROSCI.206012.2012

43. Giannakopoulou C, Korakaki E, Manoura A, Bikouvarakis S, Papageorgiou M, Gourgiotis D, et al. Significance of hypocarbia in the development of periventricular leukomalacia in preterm infants. Pediatr Int (2004) 46(3):268-73. doi:10.1111/j.1442-200x.2004.01886.x

44. Resch B, Jammernegg A, Vollaard E, Maurer U, Müller WD, Pertl B. Preterm twin gestation and cystic periventricular leucomalacia. Arch Dis Child Fetal Neonatal Ed (2004) 89(4):F315-20. doi:10.1136/adc.2003.037309

45. Collins MP, Lorenz JM, Jetton JR, Paneth N. Hypocapnia and other ventilationrelated risk factors for cerebral palsy in low birth weight infants. Pediatr Res (2001) 50(6):712-9. doi:10.1203/00006450-200112000-00014

46. Leviton A, Allred E, Kuban KC, Dammann O, O'Shea TM, Hirtz D, et al. Early blood gas abnormalities and the preterm brain. Am J Epidemiol (2010) 172(8):907-16. doi:10.1093/aje/kwq222
47. Zhang K, Zhu L, Fan M. Oxygen, a key factor regulating cell behavior during neurogenesis and cerebral diseases. Front Mol Neurosci (2011) 4:5. doi:10.3389/fnmol.2011.00005

48. Stacpoole SR, Spitzer S, Bilican B, Compston A, Karadottir R, Chandran S, et al. High yields of oligodendrocyte lineage cells from human embryonic stem cells at physiological oxygen tensions for evaluation of translational biology. Stem Cell Reports (2013) 1(5):437-50. doi:10.1016/j.stemcr.2013.09.006

49. Pistollato F, Chen HL, Schwartz PH, Basso G, Panchision DM. Oxygen tension controls the expansion of human CNS precursors and the generation of astrocytes and oligodendrocytes. Mol Cell Neurosci (2007) 35(3):424-35. doi:10.1016/j.mcn.2007.04.003

50. Gerstner B, DeSilva TM, Genz K, Armstrong A, Brehmer F, Neve RL, et al. Hyperoxia causes maturation-dependent cell death in the developing white matter. J Neurosci (2008) 28(5):1236-45. doi:10.1523/JNEUROSCI.3213-07.2008

51. Schmitz T, Ritter J, Mueller S, Felderhoff-Müser U, Chew LJ, Gallo V. Cellular changes underlying hyperoxia-induced delay of white matter development. J Neurosci (2011) 31(11):4327-44. doi:10.1523/JNEUROSCI.3942-10.2011

52. Ritter J, Schmitz T, Chew LJ, Bührer C, Möbius W, Zonouzi M, et al. Neonatal hyperoxia exposure disrupts axon-oligodendrocyte integrity in the subcortical white matter. J Neurosci (2013) 33(21):8990-9002. doi:10.1523/JNEUROSCI. 5528- 12.2013

53. Gerstner B, Bührer C, Rheinländer C, Polley O, Schüller A, Berns M, et al. Maturation-dependent oligodendrocyte apoptosis caused by hyperoxia. $J \mathrm{Neu}$ rosci Res (2006) 84(2):306-15. doi:10.1002/jnr.20880

54. Pellicer A, Greisen G, Benders M, Claris O, Dempsey E, Fumagalli M, et al. The SafeBoosC phase II randomised clinical trial: a treatment guideline for targeted near-infrared-derived cerebral tissue oxygenation versus standard treatment in extremely preterm infants. Neonatology (2013) 104(3):171-8. doi:10.1159/000351346

Conflict of Interest Statement: The authors declare that the research was conducted in the absence of any commercial or financial relationships that could be construed as a potential conflict of interest.

Received: 10 November 2014; accepted: 21 December 2014; published online: 12 January 2015.

Citation: Wellmann S, Bührer C and Schmitz T (2015) Focal necrosis and disturbed myelination in the white matter of newborn infants: a tale of too much or too little oxygen. Front. Pediatr. 2:143. doi: 10.3389/fped.2014.00143

This article was submitted to Pediatric Cardiology, a section of the journal Frontiers in Pediatrics.

Copyright (c) 2015 Wellmann, Bührer and Schmitz. This is an open-access article distributed under the terms of the Creative Commons Attribution License (CC BY). The use, distribution or reproduction in other forums is permitted, provided the original author(s) orlicensor are credited and that the original publication in this journal is cited, in accordance with accepted academic practice. No use, distribution or reproduction is permitted which does not comply with these terms. 